\title{
CARACTERÍSTICAS MORFOGÊNICAS E ESTRUTURAIS DO CAPIM-MARANDU SOB IRRIGAÇÃO E ADUBAÇÃO
}

\author{
J. A. MAGALHÃES ${ }^{1 *}$, M. S. de S. CARNEIRO ${ }^{2}$, A. C. ANDRADE ${ }^{3}$, B. H. N. RODRIGUES ${ }^{1}$, N. de L. $\operatorname{COSTA}{ }^{4}$, F. J. de S. \\ SANTOS $^{1}$, R. L. EDVAN ${ }^{5}$, R. B. de ARAÚJO NETO ${ }^{1}$ \\ Embrapa Meio-Norte ${ }^{1}$, Universidade Federal do Ceará ${ }^{2}$, Universidade Estadual do Piauí ${ }^{3}$, Embrapa Roraima ${ }^{4}$, \\ Universidade Federal do Piauí ${ }^{5}$ \\ joao.magalhaes@embrapa.br*
}

Artigo submetido em 04/05/2016 e aceito em 12/12/2016

DOI: $10.15628 /$ holos.2016.4514

\section{RESUMO}

Avaliou-se os efeitos de diferentes lâminas de irrigação e doses de nitrogênio (N) sobre as características morfogênicas e estruturais do capim-Marandu (Brachiaria brizantha cv. Marandu). O estudo foi conduzido na área experimental da EMBRAPA MeioNorte, em Parnaíba, Piauí, Brasil. Em delineamento em blocos casualizado, esquema fatorial $2 \times 4$, foram testadas lâminas de irrigação (equivalente a reposição de $50 \%$ e $80 \%$ da Evaporação do Tanque Classe "A") x doses de nitrogênio $(16,7 ; 33,3 ; 50,0$ e 66,7 kg de $\mathrm{N} /$ corte), com três repetições. Os cortes foram realizados a cada 30 dias, totalizando quatro cortes. A redução da lâmina de irrigação proporcionou decréscimos nas taxas de alongamento da folha, aparecimento de folha, comprimento final da folha e número de folhas vivas, enquanto que a taxa de senescência aumentou. A adubação nitrogenada incrementou as taxas de alongamento e aparecimento de folha, e o comprimento final da folha, no entanto, provocou redução do número de folhas vivas e a ampliação da taxa de senescência.

PALAVRAS-CHAVE: Brachiaria brizantha, irrigação de pastagem, nitrogênio.

\section{MORPHOGENETIC AND STRUCTURAL CHARACTERISTICS OF MARANDU GRASS UNDER IRRIGATION AND FERTILIZATION}

\section{ABSTRACT}

The effects of different irrigation and nitrogen $(N)$ on morphogenetic and structural characteristics of Marandu grass (Brachiaria brizantha var. Marandu), were evaluated. The study was conducted in the experimental area of EMBRAPA Mid-North in Parnaíba, Piauí, Brazil. In design in randomized blocks, factorial $2 \mathrm{x}$ 4, irrigation levels were tested (equivalent to replacement of $50 \%$ and $80 \%$ of pan evaporation Class "A") x nitrogen levels (16.7, 33.3, 50.0 and $66.7 \mathrm{~kg} \mathrm{~N} \mathrm{/}$ cutting), with three replications. Sections were made every 30 days, a total of four cuts. The reduction in water depth decreases in sheet provided elongation rate, leaf appearance, final leaf length and number of green leaves, while the increased rate of senescence. Nitrogen fertilization rates increased elongation and leaf appearance, and the final leaf length, however, caused a reduction in the number of living leaves and the expansion rate of senescence. 


\section{INTRODUÇÃO}

Morfogênese pode ser definida como a dinâmica de geração e expansão da planta no espaço (Chapman e Lemaire, 1993). O surgimento, a expansão, a senescência e a morte das folhas, definem o fluxo de biomassa do relvado e determinam o índice de área foliar (Parsons e Penning, 1988; Costa et al., 2014). Nas gramíneas em crescimento vegetativo, a morfogênese pode ser descrita por três características básicas: taxa de aparecimento de folhas, taxa de alongamento e duração de vida da folha (Chapman e Lemaire, 1993; Zanine et al., 2005; Vieira e Mochel Filho, 2010). Estas características, embora programadas geneticamente, são influenciadas pela temperatura ambiente, disponibilidade hídrica e de nutrientes no solo. A combinação das variáveis morfogênicas com os fatores ambientais determina a dinâmica do fluxo de tecidos e as características estruturais das pastagens: tamanho da folha, densidade de perfilhos e número de folhas por perfilho (Santos et al., 2012).

Por outro lado, para reduzir a estacionalidade da produção de forragens se torna indispensável a utilização de tecnologias como irrigação de pastagens, para possibilitar aumentos nas características de crescimento e de produção da planta forrageira. Para Dias Filho et al. (1989), a disponibilidade de água afeta a produção de biomassa das gramíneas, e períodos de déficit hídrico podem ser considerados os maiores limitantes climáticos para o desenvolvimento de forrageiras em ambiente tropical. Ademais, a diminuição do conteúdo de água no solo afeta acentuadamente os processos morfofisiológicos das plantas (Santos e Carlesso, 1998; BomfimSilva et al., 2011; Silva, 2013; Bomfim-Silva et al., 2014).

A produção forrageira, como resultado dos processos de crescimento e desenvolvimento, pode ter sua eficiência substancialmente melhorada pelo aumento do uso de fertilizantes, principalmente pela ação do nitrogênio, por meio da sua expressiva influência no fluxo de biomassa (Duru e Ducrocq, 2000a). O nitrogênio é um dos nutrientes que mais contribui para a produtividade das pastagens, por estar relacionado ao crescimento e perfilhamento das plantas (Carvalho et al., 2006; Galzerano e Morgado, 2007). Fagundes et al. (2005) observaram comportamento linear positivo da expansão foliar e do comprimento final da folha do capim Brachiaria decumbens ao ser adubado com doses de 75 a $300 \mathrm{~kg}$ de N/ha. Assim, o sucesso na utilização de pastagens também depende, além da espécie forrageira, da disponibilidade hídrica e de nutrientes, do entendimento dos mecanismos morfofisiológicos e da sua interação com o ambiente, ponto fundamental para suportar tanto o crescimento quanto a manutenção da capacidade produtiva da pastagem e reduzir as perdas por senescência (Garcez Neto et al., 2002).

Esse experimento teve por objetivo avaliar os efeitos de diferentes lâminas de água de irrigação e da adubação nitrogenada sobre as características morfogênicas e estruturais do capim Brachiaria brizantha cv. Marandu. 


\section{MATERIAL E MÉTODOS}

O trabalho foi realizado na Embrapa Meio-Norte, em Parnaíba, Piauí, durante o período de agosto a dezembro de 2007. O clima é do tipo Aw', segundo classificação de Köppen, com vento moderado e umidade relativa do ar de moderada a alta. A precipitação anual média é de $1.300 \mathrm{~mm}$ e o período chuvoso se concentra nos meses de janeiro a junho. O solo do local foi classificado como Latossolo Amarelo distrófico, com as seguintes características principais: solo profundo, acentuadamente drenado, de textura variando de média a argilosa no horizonte $B$, densidade do solo relativamente alta $\left(1,3\right.$ a 1,6 $\left.\mathrm{kg} \mathrm{m}^{3}\right)$ com valores médios de $846 \mathrm{~g} / \mathrm{kg}$ de areia, $58 \mathrm{~g} / \mathrm{kg}$ de silte e $95 \mathrm{~g} / \mathrm{kg}$ de argila. (MELO et al., 2004). No início do experimento apresentou as seguintes características químicas: $\mathrm{MO}=15,28 \mathrm{~g} / \mathrm{kg} ; \mathrm{pH}\left(\mathrm{H}_{2} \mathrm{O}\right)=5,48 ; \mathrm{P}=13,45 \mathrm{mg} / \mathrm{dm}^{3} ; \mathrm{K}=0,04$ $\mathrm{cmol}_{\mathrm{d}} / \mathrm{dm}^{3} ; \mathrm{Ca}=1,51 \mathrm{cmol} / \mathrm{dm}^{3} ; \mathrm{Mg}=0,44 \mathrm{cmol} / \mathrm{dm}^{3} ; \mathrm{Na}=0,16 \mathrm{cmol}_{\mathrm{c}} / \mathrm{dm}^{3} ; \mathrm{Al}=0,01$ $\mathrm{cmol}_{\mathrm{c}} / \mathrm{dm}^{3} ; \mathrm{H}+\mathrm{Al}=1,25 \mathrm{cmol}_{\mathrm{c}} / \mathrm{dm}^{3} ; \mathrm{S}=2,14 \mathrm{cmol} \mathrm{c}_{\mathrm{c}} / \mathrm{dm}^{3} ; \mathrm{CTC}=3,40 \mathrm{cmol} / \mathrm{dm}^{3} ; \mathrm{V}=63,04 \% ; \mathrm{m}=$ $0,69 \%$.

As propriedades físicas do solo da área experimental, segundo Melo et al. (2004), estão descritas na Tabela 1, e os dados de temperatura e precipitação durante a condução desta pesquisa estão expostos na Figura 1.

Tabela 1. Propriedades físicas de um LATOSSOLO Amarelo distrófico na Unidade de Execução de Pesquisa da Embrapa Meio-Norte em Parnaíba, Piauí.

\begin{tabular}{cccccc}
\hline $\begin{array}{c}\text { Profundidade } \\
(\mathrm{cm})\end{array}$ & Horizonte & \multicolumn{3}{c}{ Textura $(\mathrm{g} / \mathrm{kg})$} & Classificação \\
\cline { 3 - 5 } & & Areia & Silte & Argila & Textural \\
\hline $0-25$ & $\mathrm{Ap}$ & 852 & 62 & 86 & Areia Franca \\
$25-40$ & $\mathrm{AB}$ & 886 & 39 & 75 & Areia Franca \\
$40-70$ & $\mathrm{Bw}_{1}$ & 854 & 61 & 85 & Areia Franca \\
$70-120$ & $\mathrm{Bw}_{2}$ & 833 & 52 & 115 & Areia Franca \\
$>120$ & $\mathrm{Bw}_{3}$ & 807 & 77 & 116 & Franco Arenoso \\
\hline
\end{tabular}

Melo et al. (2004).

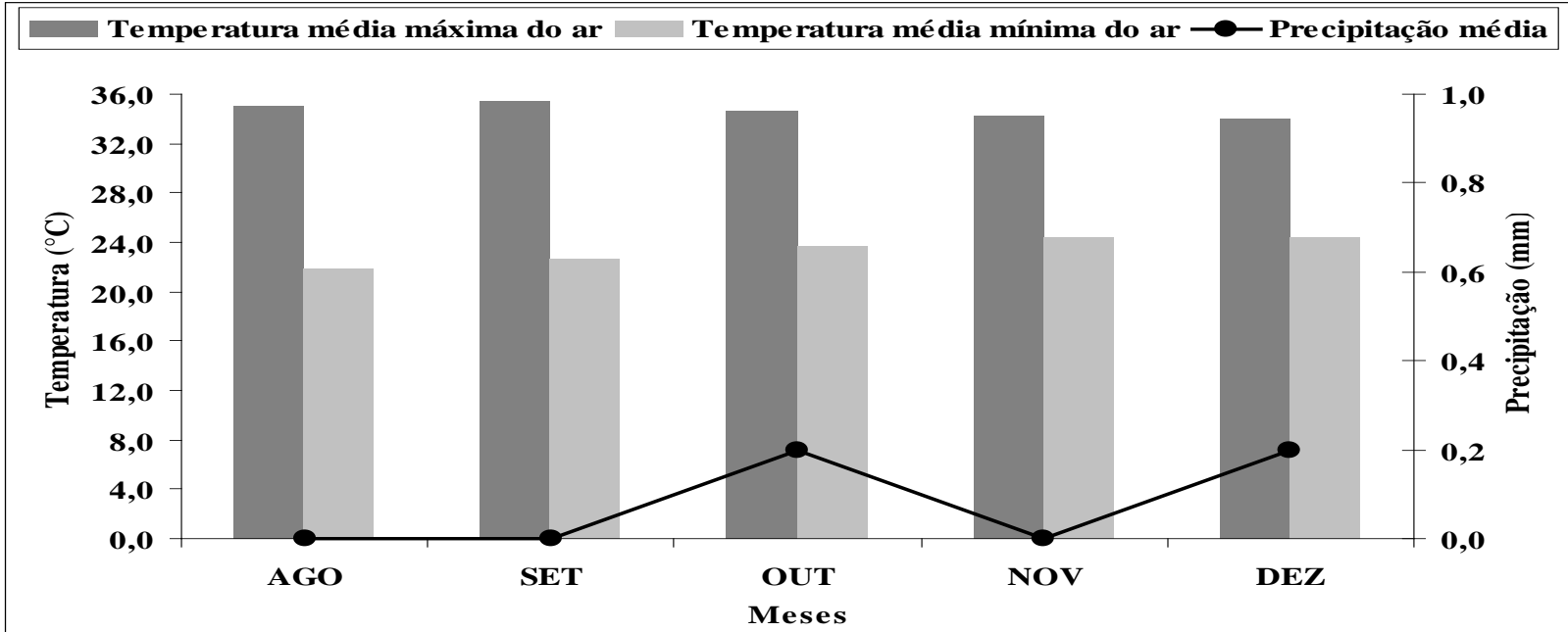

Figura 1 - Temperatura media máxima, temperatura media mínima e precipitação média de agosto a dezembro de 2007. Parnaíba, Piauí. 
As parcelas experimentais mediam $3 \mathrm{~m} \times 8 \mathrm{~m}$, e foram implantadas no início do período chuvoso, aplicando-se, em fundação, a dosagem equivalente a $50 \mathrm{~kg} / \mathrm{ha}$ de $\mathrm{P}_{2} \mathrm{O}_{5}$, na forma de superfosfato triplo e $40 \mathrm{~kg} / \mathrm{ha}$ de $\mathrm{K}_{2} \mathrm{O}$, na forma de cloreto de potássio, além de $45 \mathrm{~kg} / \mathrm{ha}$ de nitrogênio na forma de ureia, parceladas em duas aplicações, uma no plantio e outra 30 dias após.

Utilizou-se o delineamento em blocos casualizado, esquema fatorial $2 \times 4$, foram testadas lâminas de irrigação (equivalente a reposição de $50 \%$ e $80 \%$ da Evaporação do Tanque Classe " $A$ ") $x$ doses de nitrogênio $(16,7 ; 33,3 ; 50,0$ e $66,7 \mathrm{~kg}$ de N/corte), com três repetições. O corte de uniformização foi realizado em agosto. Para coleta de dados, foram realizados quatro cortes cada 30 dias (setembro, outubro, novembro, dezembro), a $20 \mathrm{~cm}$ do solo.

A adubação nitrogenada, na forma de ureia, foi aplicada a lanço e de acordo com as quantidades estabelecidas nos tratamentos. Durante o período experimental foram aplicados 66,$8 ; 133,2 ; 200,00$ e $266,8 \mathrm{~kg}$ de N/ha, respectivamente.

$\mathrm{Na}$ irrigação foi utilizado um sistema de aspersão convencional fixo, de baixa pressão e vazão, utilizando-se um turno de rega de três dias, cujo espaçamento entre linhas laterais e entre aspersores foi de $12 \mathrm{~m} \times 12 \mathrm{~m}$. Durante o período experimental, os valores das lâminas totais de irrigação aplicadas nos tratamentos dos níveis de irrigação foram de 471,99 mm (50\% de ECA) e $755,18 \mathrm{~mm}$ (80\% de ECA).

Para coleta dos dados de morfogênese, foram marcados com cordas de nylon coloridas dois perfilhos basilares por parcela, e com o uso de uma régua, foram realizadas medições, duas vezes por semana, anotando-se os valores em planilhas previamente elaboradas. A lâmina foliar foi medida até sua completa expansão, ou seja, até o aparecimento da lígula. O comprimento da lâmina emergente foi medido do seu ápice até a lígula da última folha expandida, ou até sua completa expansão. A senescência foi identificada pelo amarelecimento do ápice laminar, onde foram consideradas como folha senescente (morta) aquelas que apresentaram mais que $50 \%$ de sua lâmina amarelecida.

Com os dados registrados nas planilhas, foram calculadas as seguintes variáveis: Taxa de Alongamento de Folhas (TAIF - cm/perfilho/dia) - foi obtida subtraindo-se o comprimento total inicial de lâminas foliares do comprimento total final e dividindo-se a diferença pelo número de dias envolvidos; Taxa de Aparecimento de Folhas (TApF - folhas/perfilho/dia) - foi obtida pela divisão do número de folhas completamente expandidas (lígula exposta) surgidas por perfilho pelo número de dias envolvidos; Taxa de Senescência de Folhas (TSF - cm/perfilho/dia) - foi calculada dividindo-se o comprimento final total do tecido senescente, pelo número de dias envolvidos; Comprimento Final da Lâmina Foliar (CFLF - $\mathrm{cm}$ ): foram medidas as folhas completamente expandidas, desde sua inserção na lígula até o ápice foliar. Número de Folhas Vivas por perfilho (NFV - unidade) - foi determinado o número de folhas emergentes e expandidas do perfilho, desconsiderando-se as que apresentavam mais de $50 \%$ de senescência.

\section{RESULTADOS E DISCUSSÃO}

Não houve interações significativas $(P>0,05)$ entre lâminas de irrigação e adubação nitrogenada sobre a taxa de alongamento de folhas (TAIF) do capim B. brizantha cv. Marandu 
(Tabela 2), no entanto, foi observada diferença significativa $(P<0,01)$ entre as lâminas de irrigação aplicadas. A redução da TAIF entre as lâminas irrigação de 80 e 50\% de ECA foi de $25,46 \%$.

De acordo com Hsiao (1973) e Ludlow e Ng (1997), o alongamento da folha é um dos processos fisiológicos mais sensíveis à umidade do solo, pois a planta cessa o crescimento de folhas e raízes muito antes que os processos de fotossíntese e divisão celular sejam afetados. Dias Filho et al. (1989), observaram que o estresse hídrico reduziu a taxa de alongamento foliar em plantas de capim-tobiatã (P. maximum). Conforme Morales (1998), dependendo do grau da disponibilidade de água no solo, a TAIF pode ser reduzida em até $60 \%$, refletindo negativamente na produção de forragem.

Tabela 2 - Taxa de alongamento de folhas (TAIF) do capim Brachiaria brizantha cv. Marandu, sob irrigação e adubação nitrogenada (N). Parnaíba, Piauí.

\begin{tabular}{|c|c|c|c|c|c|c|c|}
\hline \multirow{3}{*}{$\begin{array}{l}\text { Lâminas } \\
\text { irrigação }\end{array}$} & \multicolumn{4}{|c|}{ Doses de $\mathrm{N}$ (kg/ha $\mathrm{x}$ corte) } & \multirow{3}{*}{ Média** } & \multirow{3}{*}{$\begin{array}{l}\text { Equação de } \\
\text { regressão }\end{array}$} & \multirow{3}{*}{$\mathrm{R}^{2}$} \\
\hline & 16,7 & 33,3 & 50,0 & 66,7 & & & \\
\hline & \multicolumn{4}{|c|}{ TAlF (cm/perfilho/dia) } & & & \\
\hline $50 \%$ de ECA & 1,19 & 0,97 & 1,39 & 1,24 & $1,20^{B}$ & Sem ajuste & - \\
\hline $80 \%$ de ECA & 1,46 & 1,41 & 1,89 & 1,70 & $1,61^{A}$ & $\begin{array}{l}\hat{y}=1,3140 \\
+0,00734 N\end{array}$ & 0,51 \\
\hline
\end{tabular}

CV (\%) $\quad 17,77$

** Na coluna, médias seguidas por letras distintas diferem entre si, pelo teste de Tukey a $5 \%$ de probabilidade. ECA = Evaporação do Tanque Classe $A$

Houve efeito linear positivo dos níveis crescentes de nitrogênio sobre a TAIF do capimmarandu, fato registrado apenas na lâmina de irrigação de $80 \%$ de ECA, demonstrando que, na ausência de déficit hídrico, a adubação nitrogenada promove efeito marcante na TAlF de gramíneas forrageiras (Tabela 2). Trabalhando em casa de vegetação, Alexandrino et al. (2004) reportaram que a aplicação de nitrogênio incrementou significativamente a TAlF do capimmarandu, chegando a 185,24 e $264,32 \%$, respectivamente, para as plantas que receberam 20 e $40 \mathrm{mg}$ de $\mathrm{N} / \mathrm{dm}^{3} /$ semana.

A taxa de aparecimento de folhas (TApF) do capim-marandu não foi alterada significativamente $(P>0,05)$ pelos tratamentos testados (Tabela 3). Andrade et al. (2005), Cunha et al. (2007) e Alves et al. (2008) também não encontraram influência da irrigação na TApF. De acordo com Nabinger e Pontes (2001), o efeito de limitações hídricas e nutricionais sobre a TApF não aparece de forma clara na literatura disponível, provavelmente porque sendo o parâmetro central do programa morfogenético das plantas, esta seja a última característica que a planta penalizaria.

Segundo Cruz e Boval (2000) e Suplick et al. (2002), os estudos sobre TApF das gramíneas sob efeito de nitrogênio têm apresentado resultados conflitantes. Como neste experimento, Magalhães (2007) e Silva et al. (2009) também não encontraram efeitos das dosagens de $N$ sobre a TApF em capim-Tanzânia e capim-buffel, respectivamente. Ao passo que, Alexandrino et al. (2004) reportaram incremento linear positivo desta variável, quando foram aplicados três doses 
de nitrogênio (0, 20 e $40 \mathrm{mg}$ de $\mathrm{N} / \mathrm{dm}^{3}$ x semana) em B. brizantha $\mathrm{cv}$. Marandu, cultivado em casa de vegetação. Respostas semelhantes foram descritas por Costa et al. (2006), em $P$. maximum cv. Vencedor, e Costa et al. (2009), em B. brizantha cv. Xaraés.

Gastal e Lemaire (1988) consideraram que o efeito do nitrogênio na TApF de gramíneas é muito pequeno, sendo mais expressivo no tamanho da folha, levando a um importante aumento na taxa de alongamento foliar. Por outro lado, Andrade et al. (2005) enfatizaram que a TApF é fortemente influenciada pela temperatura.

Tabela 3 - Taxa de aparecimento de folhas (TApF) do capim Brachiaria brizantha cv. Marandu, sob irrigação e adubação nitrogenada (N). Parnaíba, Piauí.

\begin{tabular}{|c|c|c|c|c|c|c|}
\hline \multirow{3}{*}{$\begin{array}{l}\text { Lâminas de } \\
\text { irrigação }\end{array}$} & \multicolumn{4}{|c|}{ Doses de $\mathrm{N}$ (kg/ha $x$ corte) } & \multirow{3}{*}{ Médias } & \multirow{3}{*}{ Equação de regressão } \\
\hline & 16,7 & 33,3 & 50,0 & 66,7 & & \\
\hline & \multicolumn{4}{|c|}{ TApF (cm/perfilho/dia) } & & \\
\hline $50 \%$ de ECA & 0,111 & 0,101 & 0,119 & 0,121 & 0,113 & Sem ajuste \\
\hline $80 \%$ de ECA & 0,122 & 0,120 & 0,123 & 0,117 & 0,120 & Sem ajuste \\
\hline
\end{tabular}

ECA $=$ Evaporação do Tanque Classe $A$

A interação entre lâminas de irrigação e níveis de nitrogênio não foi significativa $(P>0,05)$ para o comprimento final da lâmina foliar (CFLF) do capim-marandu (Tabela 4). Foi observada diferença estatística $(P<0,05)$ entre as lâminas de irrigação utilizadas, com o CFLF menor para lâmina de irrigação de $50 \%$ de ECA, com 19,22 cm, demonstrando que o CFLF é influenciado pela disponibilidade hídrica do solo.

Segundo Mochel Filho (2009), o comprimento final da folha do capim-Mombaça foi reduzido de $30,51 \mathrm{~cm}$ para $25,60 \mathrm{~cm}$, quando recebeu lâminas de irrigação de $80 \%$ e 50\% de ECA. Silva et al. (2005) também reportaram que o déficit hídrico reduziu 57,74\% o comprimento final da folha do capim-Setária (Setaria anceps Stapf.). Em trabalho com capim-elefante, Barreto et al. (2001) observaram que houve redução de $28 \%$ no comprimento da lâmina foliar, passando de $69,9 \mathrm{~cm}$ nas parcelas irrigadas para $50 \mathrm{~cm}$ nas que sofreram estresse hídrico.

Tabela 4 - Comprimento final da lâmina foliar (CFLF) do capim Brachiaria brizantha cv. Marandu, sob irrigação e adubação nitrogenada (N). Parnaíba, Piauí.

\begin{tabular}{|c|c|c|c|c|c|c|c|}
\hline \multirow{3}{*}{$\begin{array}{l}\text { Lâminas } \\
\text { irrigação }\end{array}$} & \multicolumn{4}{|c|}{ Doses de $\mathrm{N}$ (kg/ha x corte) } & \multirow{3}{*}{ Médias* } & \multirow{3}{*}{ Equação de regressão } & \multirow{3}{*}{$\mathrm{R}^{2}$} \\
\hline & 16,7 & 33,3 & 50,0 & 66,7 & & & \\
\hline & \multicolumn{4}{|c|}{ CFLF $(\mathrm{cm})$} & & & \\
\hline $50 \%$ de ECA & 17,76 & 17,80 & 21,20 & 22,12 & $19,22^{B}$ & $\hat{y}=16,59908+0,063076 \mathrm{~N}$ & 0,62 \\
\hline $80 \%$ de ECA & 17,92 & 19,39 & 22,19 & 22,80 & $20,58^{A}$ & $\hat{y}=16,218018+0,104734 N$ & 0,95 \\
\hline CV (\%) 7,23 & & & & & & & \\
\hline * Médias se & idas $\mathrm{F}$ & letras & stintas & diferem & entre si, & pelo teste de Tukey a & $5 \%$ de \\
\hline HOLOS, Ano 3 & Vol. 0 & & & & & & 18 \\
\hline
\end{tabular}


probabilidade. $\mathrm{ECA}=$ Evaporação do Tanque Classe $\mathrm{A}$

Dentro de lâminas foi observado efeito linear positivo, sendo mais expressivo para lâmina de irrigação de $80 \%$ de ECA, revelando que a combinação de maiores níveis de nitrogênio e umidade do solo promove incremento no tamanho final da folha do capim-marandu. Contudo, esse efeito positivo do nitrogênio sobre o comprimento foliar pode favorecer o aumento da senescência foliar, graças ao sombreamento das camadas inferiores de folhagem (Wilman e Fisher, 1996). Vale destacar que esta variável está associada à taxa de alongamento foliar, conforme observaram Bandinelli et al. (2003) em capim-caninha (Andropogon lateralis).

Referindo-se à taxa de senescência da folha (TSF), não houve interação $(P>0,05)$ entre as lâminas aplicadas e as dosagens de nitrogênio (Tabela 5). Entretanto, esta variável foi influenciada $(P<0,05)$ pelas lâminas de irrigação, onde a lâmina de $50 \%$ de ECA apresentou um aumento de $136 \%$ a na taxa de senescência em relação a lâmina de $80 \%$ de ECA.

Tabela 5 - Taxa de senescência de folhas (TSF) do capim Brachiaria brizantha cv. Marandu, sob irrigação e adubação nitrogenada (N). Parnaíba, Piauí.

\begin{tabular}{|c|c|c|c|c|c|c|c|}
\hline \multirow{3}{*}{$\begin{array}{l}\text { Lâminas de } \\
\text { irrigação }\end{array}$} & \multicolumn{4}{|c|}{ Doses de $\mathrm{N}(\mathrm{kg} / \mathrm{ha}$ x corte) } & \multirow{3}{*}{ Médias* } & \multirow{3}{*}{ Equação de regressão } & \multirow{3}{*}{$\mathrm{R}^{2}$} \\
\hline & 16,7 & 33,3 & 50,0 & 66,7 & & & \\
\hline & \multicolumn{4}{|c|}{ TSF (cm/perfilho $x$ dia) } & & & \\
\hline $\begin{array}{l}50 \% \text { de } \\
\text { ECA }\end{array}$ & 0,34 & 0,41 & 0,46 & 0,58 & $0,45^{A}$ & $\hat{y}=0,268657+0,004432 N$ & 0,94 \\
\hline $80 \%$ de ECA & 0,18 & 0,17 & 0,18 & 0,22 & $0,19^{B}$ & $\begin{array}{c}\hat{y}=0,221427- \\
0,002803 N+0,000042 N^{2}\end{array}$ & 0,99 \\
\hline CV (\%) & 16,88 & & & & & & \\
\hline
\end{tabular}

Santos et al. (2004) reportaram que gramíneas mantidas com menor disponibilidade de água no solo apresentaram TSF superior àquelas mantidas sob irrigação. Em casa de vegetação, Mattos et al. (2005) encontraram TSF de $0,32 \mathrm{~cm}$ para $B$. brizantha em experimento conduzido com diferentes níveis de umidade no solo. Pereira e Chaves (1993), também citaram aumento na taxa de senescência em situações de escassez de água no solo. Ressalta-se que elevada taxas de senescência foliar implicará na redução na produção de forragem de qualidade, o que pode comprometer a produção animal.

Dentro de lâminas de irrigação, a análise de regressão revelou efeito linear positivo e efeito quadrático, para $50 \%$ e $80 \%$ de ECA, respectivamente. A TSFmax $(0,22 \mathrm{~cm})$ foi obtida com a aplicação de $66,7 \mathrm{~kg}$ de N/ha $x$ corte, ou seja, $800 \mathrm{~kg}$ de N/ha $\mathrm{x}$ ano. O aumento na taxa de senescência foliar atribuído à adubação nitrogenada é devido a capacidade do nitrogênio de estimular o metabolismo da planta, o que proporciona maior renovação de tecidos e antecipa suas fases fenológicas. Assim, Duru e Ducrocq (2000b) observaram aumento na senescência de folhas em Dactilys glomerata, adubado com $120 \mathrm{~kg}$ de $\mathrm{N} / \mathrm{ha}$, quando comparado ao não adubado. O capim-estrela (Cynodon plectostachyus) apresentou aumentos crescentes na 
senescência de folhas, depois de adubado com 0, 25 e $50 \mathrm{~kg}$ de N/ha em 49 dias de avaliação (Romero et al., 1998).

O número de folhas vivas (NFV) apresentou significância $(P<0,05)$ apenas para os níveis de irrigação aplicados (Tabela 6), sendo as médias proporcionais às lâminas utilizadas: $50 \%$ ECA $(5,52 \mathrm{FV})$ e $80 \%$ de ECA $(5,88 \mathrm{FV})$.

Tabela 6 - Número de folhas vivas (NFV) do capim Brachiaria brizantha cv. Marandu, sob irrigação e adubação nitrogenada (N). Parnaíba, Piauí.

\begin{tabular}{|c|c|c|c|c|c|c|}
\hline \multirow{3}{*}{$\begin{array}{l}\text { Lâminas de } \\
\text { irrigação }\end{array}$} & & oses d & $\mathrm{kg} / \mathrm{ha}$ & & \multirow{3}{*}{ Médias* } & \multirow{3}{*}{$\begin{array}{c}\text { Equação de } \\
\text { regressão }\end{array}$} \\
\hline & 16,7 & 33,3 & 50,0 & 66,7 & & \\
\hline & \multicolumn{4}{|c|}{ NFV/perfilho } & & \\
\hline $50 \%$ de ECA & 5,41 & 5,33 & 5,33 & 6,00 & $5,52^{B}$ & Sem ajuste \\
\hline $80 \%$ de ECA & 5,70 & 5,91 & 5,75 & 6,16 & $5,88^{A}$ & Sem ajuste \\
\hline CV (\%) & 6,68 & & & & & \\
\hline
\end{tabular}

A menor disponibilidade hídrica limita o tamanho de folhas individuais do capim-marandu e reduz o número de folhas vivas porque diminui a taxa de alongamento foliar e a taxa de senescência. Alves et al. (2008) relataram que a menor disponibilidade de água no solo reduziu significativamente $o$ número de folhas vivas de $B$. decumbens, fato também descrito por Fagundes et al. (2006), que observaram redução de $10 \%$ no NFV desta gramínea no período de menor precipitação pluviométrica. Todavia, autores como Cunha et al. (2007) e Mochel Filho (2009) não encontraram efeitos dos níveis de irrigação sobre o NFV dos capins Tanzânia e Mombaça, respectivamente.

Não foi observada influência $(P>0,05)$ das dosagens de nitrogênio aplicadas sobre o NFV. Esta variável é uma característica fortemente influenciada geneticamente (Davies, 1988), todavia pode sofrer discreta influência da adubação nitrogenada. Trabalhando na região de Rondonópolis, Mato Grosso, com níveis de zero a $500 \mathrm{~kg} / \mathrm{ha} x$ ano de nitrogênio, Cabral (2008) revelou que adubação nitrogenada promoveu efeito linear ( $\hat{y}=4,1781+0,000596 \mathrm{~N} ; R^{2}=0,97$ ) no $\mathrm{NFV} /$ perfilho da $B$. brizantha $\mathrm{cv}$. Xaraés apenas durante o período chuvoso, não influenciando ao longo do ano. Em casa de vegetação, Silva et al. (2009) observaram que a NFV dos capins $B$. brizantha cv. Marandu e $B$. decumbens apresentaram efeito quadrático diante dos níves de nitrogênio aplicados, enquanto Fagundes et al. (2006) reportaram que o NFV do capim $B$. decumbens não respondeu à adubação nitrogenada.

Em geral, as médias do NFV/perfilho observadas neste experimento estão de acordo com Corsi et al. (1994), pois, segundo estes autores, o número médio de folhas por perfilho em equilíbrio entre o aparecimento e senescência do capim-marandu está entre 5 e 7 folhas.

\section{CONCLUSÕES}


- A redução da lâmina de irrigação de $80 \%$ para $50 \%$ de evaporação do tanque Classe $A$ proporciona decréscimos nas taxas de alongamento e de aparecimento de folha, no comprimento final da folha e no número de folhas vivas, enquanto, a taxa de senescência é potencializada.

- Doses crescentes de nitrogênio aumentam a taxa de alongamento da folha, o comprimento final da folha e a taxa de senescência, no entanto, o numero de folhas vivas e a taxa de aparecimento de folhas são pouco influenciados.

\section{REFERÊNCIAS}

1. ALEXANDRINO, E., NASCIMENTO JÚNIOR, D. DO, MOSQUIM, P. R., REGAZZI, A. J., ROCHA, F. C. Características morfogênicas e estruturais na rebrotação da Brachiaria brizantha cv. Marandu submetida a três doses de nitrogênio. Revista Brasileira de Zootecnia, v.33, n.6, p.13721379, 2004.

2. ALVES, J. DE S., PIRES, A.J.V., MATSUMOTO, M.P. DE, RIBEIRO, G.S. Características morfológicas e estruturais da Brachiaria decumbens Stapf. submetida a diferentes doses de nitrogênio e volumes de água. Acta Veterinaria Brasilica, v.2, n.1, p.1-10, 2008.

3. ANDRADE, A.C., FONSECA, D.M. DA, LOPES, R. DOS S., NASCIMENTO JÚNIOR, D., CECON, P.R., QUEIROZ, D.S., PEREIRA, D.H.P., REIS, S.T. - Características morfogênicas e estruturais do capim-elefante 'Napier' adubado e irrigado. Ciência e Agrotecnologia, v.29, n.1, p.150159, p.2005.

4. BARRETO, G.P., LIRA, M.A., SANTOS, M.V.F., DUBEUX JUNIOR, J.C.B. Avaliação de clones de capim-elefante (Pennisetum purpureum Schum.) e de um híbrido com o milheto (Pennisetum glaucum (L.) R. Br.) submetidos a estresse hídrico. 1. Parâmetros morfológicos. Revista da Sociedade Brasileira de Zootecnia, v.30, n.1, p.1-6, 2001.

5. BANDINELLI, D.G., TABELAS, F.L.F. DE, GONÇALVES, E.N., ROCHA, M.G. Variáveis morfogênicas de Andropogon lateralis Nees submetido a níveis de nitrogênio nas quatro estações do ano. Ciência Rural, v.33, n.1, p.71-76, 2003.

6. BASTOS, E.A., ANDRADE JÚNIOR, A.S., RODRIGUES, B.H.N. Boletim agrometeorológico de 2007 para o Município de Parnaíba, Piauí. Teresina: Embrapa Meio-Norte. 2008. 37 p.

7. BONFIM-SILVA, E.M., SILVA, M.C., SCHLICHTING, A.F., PORTO, R.A., SILVA, T.J.A. AND KOETZ, M. Desenvolvimento e produção de capim-convert HD364 submetido ao estresse hídrico. Revista Agro@mbiente, 8, 134-141, 1014.

8. BONFIM-SILVA, E.M., SILVA, T.J.A., CABRAL, C.E.A., KROTH, B.E. AND REZENDE, D. Desenvolvimento inicial de gramíneas submetidas ao estresse hídrico. Revista Caatinga, 24, 180-186, 2011.

9. CABRAL, W.B. Morfogênese e produção de biomassa em Brachiaria brizantha cv. Xaraés submetido a diferentes doses de nitrogênio. Cuiabá, 100f. 2008. Dissertação Mestrado. Universidade Federal do Mato Grosso. 
10. CARVAlHO, G.G.P. de, FERNANDES, F.E. de P., PIRES, A.J.V. ZANINE, A.M. Características morfogênicas, padrões de desfolhação e qualidade de gramíneas tropicais. Revista Electrónica de Veterinária, v.7, N.2, p.1-33, fevereiro, 2006.

11. CHAPMAN, D.F., LEMAIRE, G. Morphogenetic and structural determinants of plant regrowth after defoliation. In: Baker, M.J. (Ed.). Grasslands for Our World. Wellington: SIR Publishing, p.55-64. 1993.

12. CORSI, M., BALSALOBRE, M.A.A., SANTOS, P.M., SILVA, S.C. Bases para o estabelecimento do manejo de pastagens de braquiária. In: SIMPÓSIO SOBRE MANEJO DE PASTAGENS. Piracicaba, 1994. Anais... Piracicaba: FEALQ. 1994. p.249-266.

13. COSTA, N. de L., MORAES, A. de, CARVALHO, P.C.F., MONTEIRO, A.L.G., MOTTA, A.C.V., SILVA, A.L.P., OLIVEIRA, R.A. Morfogênese de Trachypogon plumosus sob calagem, adubação e idades de rebrota. Archivos de Zootecnia, v. 63, p. 109-120, 2014.

14. COSTA, N.de L., PAULINO, V.T., MAGALHÃES, J.A. Produção de forragem, composição química e morfogênese de Panicum maximum cv. Vencedor sob diferentes níveis de adubação nitrogenada. Revista Científica de Produção Animal, v.8, n.1, p.66-72, 2006.

15. COSTA, N.de L., PAULINO, V.T., MAGALHÃES, J.A., TOWNSEND, C.R., PEREIRA, R.G. de A. Produção de forragem, composição química e morfogênese de Brachiaria brizantha cv. Xaraés sob diferentes níveis de nitrogênio. PUBVET, v.3, n.17, Art\#574, 2009.

16. CRUZ, P., BOVAL, M. Effect of nitrogen on some traits of temperate and tropical perennial forage grasses. In: LEMAIRE, G., HODGSON, J., MORAES, A., CARVALHO, P.C. DE F., NABINGER, C. (Eds.). Grassland Ecophysiology and Grazing Ecology. New York, CAB International. 2000. p.151-168.

17. CUNHA, F.F., SOARES, A.A., PEREIRA, O.G., LAMBERTUCCI, D.M., ABREU, F.V. S. Características morfogênicas e perfilhamento do Panicum maximum Jacq. cV. Tanzânia irrigado. Ciência Agrotécnica, v.31, n.3, p.628-635, 2007.

18. DAVIES, A. The regrowth of grass swards. In: JONES, M.B., LAZENBY, A. (Eds.). The grass crop. London, Chapman and Hall. 1988. p.85-127.

19. DIAS FILHO, M.B., CORSI, M., CUSATO, S. Respostas morfológicas de Panicum maximum, Jacq. cv. Tobiatã ao estresse hídrico. Pesquisa Agropecuária Brasileira, v.24, n.7, p.893-898, 1989.

20. DURU, M., DUCROCQ, H. Growth and senescence of the successive grass leaves on a tiller ontogenic development and effect of temperature. Annals of Botany, v.85, n.5, p.635-643, 2000a.

21. DURU, M., DUCROCQ, H. Growth and senescence of the successive leaves on a Cocksfoot tiller. Effect of nitrogen and cutting regime. Annals of Botany, v.85, n.5, p.645-653, 2000b.

22. FAGUNDES, J.L., FONSECA, D.M., GOMIDE, J.A., NASCIMENTO JUNIOR, D., VITOR, C.M.T., MORAIS, R.V., MISTURA, C., REIS, G.C., MASTUSCELLO, J.A. Acúmulo de forragem em pastos de Brachiaria decumbens adubados com nitrogênio. Pesquisa Agropecuária Brasileira, v.40, n.4, p.397-403, 2005. 
23. FAGUNDES, J.L., FONSECA, D.M., MISTURA, C., MORAIS, R.V., VITOR, C.M.T., GOMIDE, J.A., NASCIMENTO JUNIOR, D., CASAGRANDE, D.R., COSTA, L.T. Características morfogênicas e estruturais do capim-braquiaria em pastagem adubada com nitrogênio avaliadas nas quatro estações do ano. Revista Brasileira de Zootecnia, v.35, n.1, p.21-29, 2006.

24. GALZERANO, L., MORGADO, E.S. Respostas de plantas forrageiras a doses de nitrogênio. Revista Electrónica de Veterinária, v.7, p. 1-5, fevereiro, 2007.

25. GARCEZ NETO, A.F., NASCIMENTO JUNIOR, D., REGAZZI, A. J., FONSECA, D.M., MOSQUIM, P.R., GOBBI, K.F. Respostas morfogênicas e estruturais de Panicum maximum cv. Mombaça sob diferentes níveis de adubação nitrogenada e alturas de corte. Revista Brasileira de Zootecnia, v.31, n.5, p.1890-1900, 2002.

26. GASTAL, F., LEMAIRE, G. Study of a tall fescue sward growth under nitrogen deficiency conditions. In: PROCEEDINGS GENERAL MEETING OF THE EUROPEAN GRASSLAND FEDERATION, 12., 1988, Dublin, Ireland. Proceedings... Dublin: IGAPA, 1988 p.323-327.

27. HSIAO, T. C. Plant response to water stress. Annual Review of Plant Physiology, v.24, p.519570, 1973.

28. LUDLOW, M.M., NG, T.T. Leaf elongation rate in Panicum maximum var. Trichoglume following removal of water stress. Australian Journal of Plant Physiology, v.4, n.2, p.263-272, 1997.

29. MAGALHÃES. M.A. Fluxo de tecido e produção de capim-Tanzânia irrigado sob diferentes densidades de plantas e doses de nitrogênio. Viçosa, 2007. 94f. Dissertação Mestrado. Universidade Federal de Viçosa.

30. MATTOS, J.L.S. de, GOMIDE, J.A., HUAMAN, C.A.M.Y. Crescimento de espécies do gênero Brachiaria, sob déficit hídrico, em casa de vegetação. Revista Brasileira de Zootecnia, v.34, n.3, p.746-754, 2005.

31. MELO, F.B., CAVALCANTE, A.C., ANDRADE JÚNIOR, A.S. BASTOS, E.A. Levantamento detalhado dos solos da área da Embrapa Meio-Norte/UEP de Parnaíba. Teresina: Embrapa Meio-Norte. 26 p. 2004. (Documentos, 89).

32. MOCHEL FILHO, W. DE J.E. Fluxo de biomassa, produção de forragem e composição quimicobromatológica do capim-Mombaça sob adubação e irrigação. Fortaleza, 2009. $96 f$. Dissertação Mestrado. Universidade Federal do Ceará.

33. MORALES, A.A. Morfogênese e repartição de carbono em Lotus corniculatus L cv. São Gabriel sob o efeito de restrições hídricas e luminosas. Porto Alegre, 1998. 74f. Dissertação Mestrado. Universidade Federal do Rio Grande do Sul.

34. NABINGER, C., PONTES, L.S. Morfogênese de plantas forrageiras e estrutura do pasto. In: REUNIÃO ANUAL DA SOCIEDADE BRASILEIRA DE ZOOTECNIA, 38, Piracicaba, Brasil. Anais... Piracicaba: FEALQ, 2001. p.755-770.

35. PARSONS, A.J., PENNING, P.D. The effect of the duration of regrowth on photosynthesis, leaf death and the average rate of growth in a rotationally grazed sward. Grass and Forage Science, v.43, n.1, p.15-27, 1988.

36. PEREIRA, J.S., CHAVES, M.M. Plant water deficits in Mediterranean ecosystems. In: SMITH, J.A.C., GRIFFITHS, H. (Eds.). Water deficits: plant responses from cell to community. Oxford, Bios Scientific Publishers, 1993. p.237-252. 
37. ROMERO, C., ALFONSO, S., MEDINA, R., FLORES, R. Efecto de la fertilización nitrogenada sobre los componentes morfológicos del pasto estrella (Cynodon plectostachyus) en la Zona de Bajo Tocuyo, Estado Falcón. Zootecnia Tropical, v..16, n.1, p.41-60,1998.

38. SANTOS, A.M., CAMPOSTRINI, E., ABREU, J.B.R., BRÁS, T.G.S., SILVEIRA, J.P.F., LOTIERZO, V., PATEL, J., MACHADO NETO, O.R., MAJEROWICS, N., MÉDICI, L. O., CAETANO, V.S., PÁDUA, F.T., SOUZA, M. Resposta ao estresse hídrico de cinco gramíneas tropicais cultivadas: II. Taxas de alongamento e senescência foliar do perfilho principal. In: SYMPOSIUM ON GRASSLAND ECOPHYSIOLOGY AND GRAZING ECOLOGY. 2, 2004., Curitiba, Brasil. Proceedings... Curitiba: UFPR. 3p.

39. SANTOS, M.E.R., FONSECA, D.M. DA, GOMES, V.M., SILVA, P.S., SILVA, G.P., Castro, M.R.S. Correlações entre características morfogênicas e estruturais em pastos de capim-braquiária. Ciência Animal Brasileira, v.13, n.1, p.49-56, 2012.

40. SANTOS, R., CARLESSO, R. Déficit hídrico e os processos morfológicos e fisiológicos das plantas. Revista Brasileira de Engenharia Agrícola e Ambiental, v.2, n.3, p.287-294, 1998.

41. SILVA, C.C.F., BONOMO, P., PIRES, A.J.V., PATES, N.M.S., SANTOS, L.C. Características morfogênicas e estruturais de duas espécies de braquiária adubadas com diferentes doses de nitrogênio. Revista Brasileira de Zootecnia, v.38, n.4, p. 657-661, 2009.

42. SILVA, M.M.P., VASQUEZ, H. M., BRESSAN-SMITH, R.E., SILVA, J.C., ERBESDOBLER, E.D., ANDRADE JUNIOR, P.S.C. Respostas morfogênicas de gramíneas forrageiras tropicais sob diferentes condições hídricas do solo. Revista Brasileira de Zootecnia, v.34, n.5, p.1493-1504, 2005.

43. SILVA, P.M.P. Tolerância ao déficit hídrico em Panicum maximum. Campo Grande, 2013. 52f. Dissertação Mestrado. Universidade Federal do Mato Grosso do Sul.

44. SUPLICK, M.R., READ, J.C., MATUSON, M.A., JOHNSON, J.P. Switchgrass leaf appearance and lamina extension rates in response to fertilizer nitrogen. Journal of Plant Nutrition, v.25, n.10, p.2115-2127, 2002.

45. VIEIRA, M.M.M.; MOCHEL FILHO, W.J.E. Influência dos fatores abióticos no fluxo de biomassa e na estrutura do dossel. Archivos de Zootecnia, v.59, n.6, p.15-24, 2010.

46. WILMAN, D., FISHER, A. Effects of interval between harvests and application of fertilizer $\mathrm{N}$ in spring on the growth of perennial ryegrass in a grass/white clover sward. Grass and Forage Science, v.51, n.1, p.52-57, 1996.

47. ZANINE, A.M., SANTOS, E.M., OLIVEIRA, J.S., FERREIRA, D.J. Modernas estratégias no manejo do pastejo das gramíneas do gênero Brachiaria e Cynodon. Revista Eletrônica de Medicina Veterinária, v.6, n.11, novembre, 2005. 